\title{
Pathways to independence: towards producing and using trustworthy evidence
}

A global team of influential researchers, clinicians, regulators, and citizen advocates suggest how we can start to build an evidence base for healthcare that is free of commercial influences

Ray Moynihan assistant professor ${ }^{1}$, Lisa Bero professor, ${ }^{2}$, Sue Hill senior adviser ${ }^{3}$, Minna Johansson family physician ${ }^{4}$, Joel Lexchin professor emeritus ${ }^{5}$, Helen Macdonald UK research editor ${ }^{6}$, Barbara Mintzes associate professor ${ }^{2}$, Cynthia Pearson executive director ${ }^{7}$, Marc A Rodwin professor ${ }^{8}$, Anna Stavdal president elect ${ }^{9}$, Jacob Stegenga reader ${ }^{10}$, Brett D Thombs professor ${ }^{11}$, Hazel Thornton honorary visiting fellow ${ }^{12}$, Per Olav Vandvik professor ${ }^{13}$, Beate Wieseler head of department ${ }^{14}$, Fiona Godlee editor in chief $^{6}$

${ }^{1}$ Institute for Evidence Based Healthcare, Bond University, Gold Coast, Queensland, Australia; ${ }^{2}$ School of Pharmacy and Charles Perkins Centre, Faculty of Medicine and Health, University of Sydney, Camperdown, Australia; ${ }^{3}$ Science Division, World Health Organization, Geneva, Switzerland; ${ }^{4}$ Cochrane Sustainable Healthcare, Lund, Sweden; ${ }^{5}$ School of Health Policy and Management, York University, Toronto, Ontario, Canada; ${ }^{6}$ The BMJ, London, UK; ${ }^{7}$ National Women's Health Network, Washington, DC, USA; ${ }^{8}$ Suffolk University Law School, Boston, MA, USA; ${ }^{9}$ Wonca World, Oslo, Norway; ${ }^{10}$ Department of History and Philosophy of Science, University of Cambridge, Cambridge, UK; ${ }^{11}$ Lady Davis Institute of the Jewish General Hospital and McGill University, Montreal, Quebec, Canada; ${ }^{2}$ Department of Health Sciences, University of Leicester, Leicester, UK; ${ }^{13}$ Department of Medicine, Innlandet Hospital Trust, Gjøvik, Norway; ${ }^{14}$ Drug Assessment, Institute for Quality and Efficiency in Health Care (IQWiG), Cologne, Germany

We all want to base our healthcare decisions on trustworthy evidence. Yet the landmark 2009 Institute of Medicine report identified widespread financial conflicts of interest across medical research, education, and practice. ${ }^{1}$ It highlighted that extensive industry influence may be jeopardising "the integrity of scientific investigations, the objectivity of medical education, the quality of patient care, and the public's trust in medicine."

At the same time there's increasing appreciation across nations and within clinical and scientific communities of the problem of too much medicine. ${ }^{2-5}$ Overtesting, overdiagnosis, and overtreatment divert resources from tackling genuine need, cause harm to health, and threaten health system sustainability..$^{2-5}$ Necessary tests, treatments, and diagnoses are vital, and manufacturers have rights to make profits. But it's time to ensure the scientific evaluation of tests and treatments, and dissemination of the resulting evidence, are conducted as independently as possible from industries profiting from their use.

Perspectives differ on the financial relationships between industry and health professionals, and debate is ongoing about where to draw the line between valuable collaboration and relationships that don't serve patients or the public..$^{6-8}$ Some see transparency as the best strategy, while others regard it as necessary but insufficient. We argue that endemic financial entanglement is distorting the production and use of healthcare evidence, causing harm to individuals and waste for health systems. Building on the evidence and practical examples cited below, we propose pathways towards financial independence from industry across healthcare decision making. We hope that our proposals will catalyse and inform development of more detailed recommendations for fundamental reform within research, education, and practice.

\section{Problem of financial dependence}

\section{Research}

Financial dependence on commercial companies is common within research, and in the United States almost $60 \%$ of medical research is industry funded. ${ }^{9}$ It's been shown repeatedly that published outcomes of industry sponsored studies tend to favour sponsors' products, creating a "sponsorship bias" in the evidence base that overplays benefits and underplays harms. ${ }^{10}$ In 2013, research by the German Institute for Quality and Efficiency in 
Health Care cast new light on that bias. ${ }^{11}$ It identified major discrepancies between information on product benefits and harms found in the detailed "clinical study reports" from industry funded studies and what was publicly reported from those studies in places like medical journals. ${ }^{11}$ A recent systematic review confirmed that industry sponsored trials, compared with independently funded trials, tend to find more favourable outcomes for sponsors' products. ${ }^{12}$ And aside from study funding, other financial relationships between study researchers and sponsors are also associated with favourable results. ${ }^{13}$

Sponsoring companies have obvious financial incentives to overstate product benefits and downplay harms. But these incentives are enabled by our imperfect methods of evaluation, which can be exploited in myriad ways, consciously or unconsciously, at all stages of the process. ${ }^{14}$ For example, a study design could include an unfair comparison to ensure a favourable result for the sponsor's product, or unfavourable results might not be published. ${ }^{14}$ Research synthesis can also mislead, in part because of industry influence in the original studies being synthesised. ${ }^{15}$ To make matters worse, regulatory agencies that evaluate research evidence-including the European Medicines Agency and the US Food and Drug Administration ${ }^{16}{ }^{17}$-also have financial conflicts of interest as they rely on funding from companies whose products they are evaluating.

\section{Education}

As with research, there's evidence that industry supported educational activities or advocacy can favour supporters' products. A study of 280000 US doctors found an association between accepting just one sponsored meal and higher prescribing of sponsors' medicines, with additional or costlier meals associated with even higher prescribing. ${ }^{18}$ Another study found views of key opinion leaders in journal articles strongly correlated with the interests of companies which paid them as speakers or advisers. ${ }^{19}$ There are concerns too that most advocacy organisations are now dependent on industry funding ${ }^{20}$ and fears that they may favour their financial supporters when educating their members or the public-for example, by being "silent or slow to complain" about excessive drug prices. ${ }^{21}$

\section{Practice}

Commercial influence also affects clinical practice, whether through sales representatives, guidelines, or direct payments. Industry argues it provides valuable information that helps patients, ${ }^{22}$ yet a systematic review found exposure to drug company information is generally associated with prescribing more medicines, at higher costs and lower quality. ${ }^{23}$ In 2019, a study of marketing payments by opioid makers to 67000 US doctors found an association between the amount of marketing, increased opioid prescribing, and higher rates of death. ${ }^{24}$

Clinical guidelines, which recommend treatments and can expand disease definitions, are often produced by professional associations and written by people with financial ties to interested companies ${ }^{25-27}$ and can potentially drive overuse and overdiagnosis. ${ }^{28} 29$ A 2016 study of 95 organisations producing guidelines found an association between more comprehensive conflict of interest policies and less enthusiastic

recommendations for medical products. ${ }^{30}$ Policy decisions with far reaching effects on practice, such as for reimbursement, can also be undermined when sponsored advocacy groups become part of sponsors' marketing campaigns. ${ }^{21}$

\section{Principle of independence from commercial interests}

In our view if health systems are to produce and use trustworthy evidence, and tackle the epidemic of medical excess, decision makers at every level must disentangle from those who profit from that excess. Others disagree, arguing that these financial relationships flow from a shared mission between doctors and industry to fight disease, ${ }^{6}$ and that industry-researcher collaborations and sponsored education are vital for medical progress. ${ }^{78}$ Epstein writes that restrictions on pharmaceutical promotion could reduce industry's profitability, see promising products abandoned, and reduce available drug information, arguing "distorted information is often better than no information at all." ${ }^{\text {"7 }}$ Rosenbaum has called for more careful study of how doctor-industry financial relationships affect patients and of strategies to curtail them. ${ }^{6}$ We agree on the merit of more study and that industry-researcher collaborations to develop products are valuable, but research evaluating product benefits and harms, and its dissemination, must become independent from companies selling those products.

Fundamental reforms are already under discussion nationally and globally. In 2017, responding to high drug prices which threaten health system sustainability, the World Health Organization's European regional committee debated a bigger role for public authorities in "steering research investment." 11 In July 2019 a European Ombudsman report suggested health regulators should, to the "greatest extent possible," ensure separation between people within regulatory agencies who provide advice to private companies during development of a product and those who later evaluate it. ${ }^{32}$ In September 2019, the UK Labour Party unveiled major reform proposals, including government funding of late stage clinical trials and state owned drug companies. ${ }^{33}$ More broadly there are many examples across research, education, and practice where organisations are shifting to independence from commercial influence.

\section{Pathways to independence Research}

Although industry remains a dominant funder of research, there are examples of alternative models to inform reform. For over a decade the Italian government has taxed drug companies' promotional expenditure to fund public interest research. ${ }^{34}$ For 15 years, the Drugs for Neglected Diseases initiative (DNDi) has used a public sector driven model to fund drug development, characterised by "financial and scientific independence." ${ }^{35}$ While funding has relied on public and philanthropic donors, with strategic industry engagement, the model shows not-for-profit drug development can work when it is explicitly driven by patient needs. ${ }^{35}$ Another model—promoted by US politicians for half a century but so far successfully opposed by industry-involves companies funding product testing but public regulators assigning independent research teams to do the testing. ${ }^{36}$ A North American reform group examining exorbitant drug prices and distorted research recently proposed full public funding of regulatory agencies. ${ }^{37}$

In research synthesis, another example of reform comes from Cochrane, a global not-for-profit organisation. It now requires at least two thirds of authors of systematic reviews to have no financial ties to industry. Acknowledging that this won't remove commercial bias in sponsored studies, Cochrane will also start advocating for unconflicted and independent research. Expanding public funding for research and its regulation is clearly a major challenge but the money could, in some places, 
come partly from savings from lower drug prices, less inappropriate prescribing, and collection of taxes that are currently unfairly avoided. ${ }^{38}$

Box 1 outlines our suggested pathways towards research that is free from commercial influence. They include research synthesis being conducted without industry ties and government reforms to ensure product testing and regulatory agencies are independent of industry.

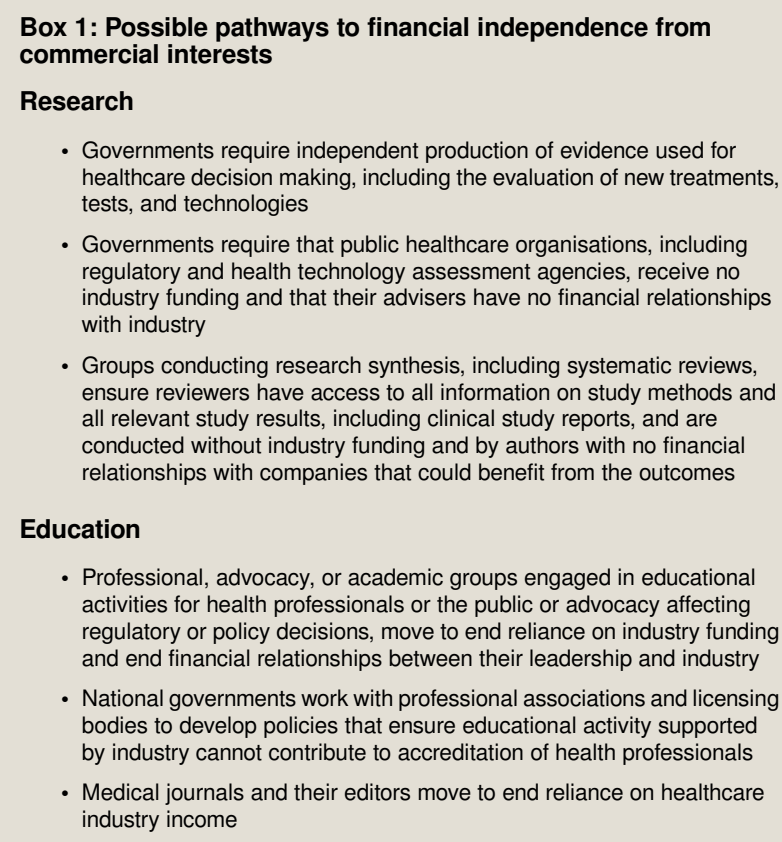

- Governments require that public healthcare organisations, including regulatory and health technology assessment agencies, receive no industry funding and that their advisers have no financial relationships with industry

- Groups conducting research synthesis, including systematic reviews, ensure reviewers have access to all information on study methods and all relevant study results, including clinical study reports, and are conducted without industry funding and by authors with no financial relationships with companies that could benefit from the outcomes

\section{Education}

- Professional, advocacy, or academic groups engaged in educational activities for health professionals or the public or advocacy affecting regulatory or policy decisions, move to end reliance on industry funding and end financial relationships between their leadership and industry

- National governments work with professional associations and licensing bodies to develop policies that ensure educational activity supported by industry cannot contribute to accreditation of health professionals

- Medical journals and their editors move to end reliance on healthcare industry income

\section{Practice}

- Professional groups, hospitals, health services, and governments prohibit marketing interactions between industry and decision makers, including practising professionals, and actively support development of healthcare information independent of commercial interests

- Professionals, policy makers, and the public move to reliance on practice guidelines produced and written by groups that have no financial relationships with industry and that have access to evidence, including research synthesis, free of industry influence

- Research funding bodies and academic institutions modify academic metrics and incentives explicitly to reward academic collaboration with public agencies and civil society groups as well as industry

These proposed pathways arise from our analysis of the relevant evidence and examples from around the world. The list is not comprehensive or definitive and is designed to inform intensified debate and development of detailed recommendations.

\section{Education}

Many organisations already provide education without industry support. Following campaigning by family doctors, the Norwegian Medical Association ruled that industry sponsored meetings and courses could no longer be counted as formal education, necessary for accreditation. ${ }^{39}$ Inspired by organisations such as the American Medical Student Association, ${ }^{40}$ doctors' groups have introduced education that is free of industry support, including in places across North America ${ }^{41}$ and India. ${ }^{42}$ Medical journals-an important educational source-have similarly started separating from industry influence. PLOS Medicine ${ }^{43}$ and Emergency Medicine Australasi ${ }^{44}$ have ended pharmaceutical advertising, and The $B M J$ now declares all drug company revenues and publishes educational articles only from writers without relevant industry ties. ${ }^{45}$ Advocacy organisations such as the US National Women's Health Network are models of freedom from industry funding.
Box 1 outlines pathways towards independence in education. They would see all groups engaged in education-including advocacy groups, medical associations, and journals-move away from financial relationships with companies selling healthcare products and reforms to bind professional accreditation to education free of industry support.

\section{Practice}

From small clinics to large organisations with thousands of physicians, there are many examples of practising clinicians ending reliance on company sales representatives. ${ }^{41}$ Doctors' groups such as No Gracias, No Advertising Please, and Mezis encourage use of information produced independently from drug makers, and some governments now fund such resources, including in Norway. ${ }^{46}$ In the field of guidelines, the new rapid recommendations-designed by the not-for-profit MAGIC Evidence Ecosystem Foundation and The BMJ - have strong restrictions on authors' financial conflicts. ${ }^{47}$ Similarly, in Denmark, doctors who advise drug companies can't be involved in national guidelines, ${ }^{48}$ and Australia now "strongly encourages" guideline panels to be free of financial conflicts, ${ }^{49}$ underscoring the need for an expanded pool of clinician researchers without industry ties.

Possible pathways to independence in practice would see policies developed within governments, hospitals, and health systems to prohibit marketing interactions between industry and healthcare decision makers, guidelines developed by people with no industry relationships, and researchers rewarded for public and civil society collaborations (box 1).

\section{First steps}

Although we support calls for more research on the effects of industry entanglement and strategies to end it, ${ }^{6}$ accumulating evidence and examples show that independence from commercial interests is both necessary and feasible. One important first step will be laws mandating comprehensive and accessible disclosure of payments made by companies selling healthcare products to those evaluating and using them. ${ }^{50}$

There are caveats to this analysis. Because of space limitations, we have focused on financial relationships rather than non-financial ones, and on healthcare rather than health more broadly. For clarity we have used the three level structure of research, education, and practice derived from the Institute of Medicine report, ${ }^{1}$ but we recognise policy is equally relevant. And our proposals are part of much wider work underway to enhance literacy about healthcare's benefits and harms ${ }^{5}$ and the risks of sponsored science.

Our proposed pathways are not comprehensive or definitive; they are designed to encourage development of more detailed practical recommendations for change, and how to fund it, among players across healthcare. Many groups are already moving away from industry influence in education and practice, but the main priority and greatest challenge is to develop models for research and evaluation independent from companies with interests in the outcomes. To deepen understanding of the problems and help develop solutions, we encourage you to respond to this article through The BMJ's rapid responses, including your positive or negative experiences of reforms. We also encourage you to sign a short statement of support available here (https://docs.google.com/forms/d/e/1FAIpQLSdj_ rtIel7Yo2vlytwz7pW_Yb6k6UIlSfOz0smTrwEwYYNdqw/ viewform?usp=sf_link) and suggest strategies and priorities. Such transformation will be slow but may be unstoppable 
because human health, the sustainability of our health systems, and trust in medical science will be the beneficiaries.

\section{Key messages}

Trustworthy evidence is required to enable well informed decisions about healthcare

Widespread financial dependence on industry brings commercial bias in research evidence, medical education and clinical practice

Such bias tends to overstate healthcare benefits and play down harms

Greater financial independence from industry is desirable and possible, with examples of reform across research, education, and practice

The proposed steps towards financial independence from commercial interests will involve major culture change

Contributors and sources: The authorship team has expertise and experience across clinical medicine, public health, law, general practice, philosophy, regulation, health technology assessment, media, citizen engagement and advocacy, guideline development, safety and quality, journals, research, research synthesis, and epidemiology. All authors write as individuals rather than representatives of the organisations in which they are employed. All authors contributed to the development of the paper, through their ideas and their work, and all were engaged in drafting the manuscript. RM initiated the idea, wrote the first draft of the manuscript, and is guarantor.

Patient and public involvement: The authors of the article include a longstanding citizen advocate for improvements in quality and safety in healthcare (HT), and the executive director of the National Women's Health Network (CP), a national citizen health advocacy organisation in the US.

Competing interests: We have read and understood BMJ policy on declaration of interests and declare the following: In 2016-19, JL was a paid consultant on two projects: one developing principles for conservative diagnosis (Gordon and Betty Moore Foundation) and a second deciding what drugs should be provided free of charge by general practitioners (Government of Canada, Ontario Supporting Patient Oriented Research Support Unit and the St Michael's Hospital Foundation). He also received payment for being on a panel at the American Diabetes Association, for a talk at the Toronto Reference Library, for writing a brief for a lawyer in a case about side effects of a drug, and from the Canadian Institutes of Health Research for presenting at a workshop on conflict of interest in clinical practice guidelines. $\mathrm{He}$ is a member of research groups that are receiving money from the Canadian Institutes of Health Research and the Australian National Health and Medical Research Council. He is a member of the Foundation Board of Health Action International and the Board of Canadian Doctors for Medicare. He receives royalties from University of Toronto Press and James Lorimer for books he has written. HM and FG work for The BMJ. Peer review and editing of the article was managed and overseen by editors who were not involved as authors.

Provenance and peer review: Commissioned; externally peer reviewed.

This article is part of a collection on commercial interests, transparency, and independence, based on ideas generated by BMJ editors in collaboration with external advisers Ray Moynihan (Bond University) and Lisa Bero (University of Sydney).

Lo B, Field MJ. Conflict of interest in medical research, education, and practice. National Academies Press, 2009

2 Organisation for Economic Cooperation and Development. Tackling wasteful spending on health. OECD, 2017.

3 Brownlee S, Chalkidou K, Doust J, etal . Evidence for overuse of medical services around the world. Lancet 2017;390:156-68. 10.1016/S0140-6736(16)32585-5 28077234

4 Morgan DJ, Dhruva SS, Coon ER, Wright SM, Korenstein D. 2019 update on medical overuse: a review. JAMA Intern Med 2019. [Epub ahead of print.]

10.1001/jamainternmed.2019.3842. 31498374

5 loannidis JPA, Stuart ME, Brownlee S, Strite SA. How to survive the medical misinformation mess. Eur J Clin Invest 2017;47:795-802. 10.1111/eci.12834 28881000

6 Rosenbaum L. Understanding bias-the case for careful study. N Engl J Med 2015:372:1959-63. 10.1056/NEJMms1502497 25970055

7 Epstein R. Causing more harm than good: conflict of interest rules thwart medical progress. Forbes 2010 Oct 26. https://www.forbes.com/sites/richardepstein/2010/10/26/causingmore-harm-than-good-conflict-of-interest-rules-thwart-medical-progress

8 Upton J. Patient advocacy: the corporate mandate. Pharmaceutical Executive 2019;39(3). http://www.pharmexec.com/patient-advocacy-corporate-mandate

9 Moses H3rd, Matheson DHM, Cairns-Smith S, George BP, Palisch C, Dorsey ER. The anatomy of medical research: US and international comparisons. JAMA 2015;313:174-89. 10.1001/jama.2014.15939 25585329
10 Jefferson T. Sponsorship bias in clinical trials-growing menace or dawning realisation? JLL Bulletin 2019. https://www.jameslindlibrary.org/articles/sponsorship-bias-in-clinicaltrials-growing-menace-or-dawning-realisation/

11 Wieseler B, Wolfram N, McGauran N, etal . Completeness of reporting of patient-relevant clinical trial outcomes: comparison of unpublished clinical study reports with publicly available data. PLoS Med 2013;10:e1001526. 10.1371/journal.pmed.1001526. 24115912

12 Lundh A, Lexchin J, Mintzes B, Schroll JB, Bero L. Industry sponsorship and research outcome. Cochrane Database Syst Rev 2017;2:MR000033.28207928

13 Ahn R, Woodbridge A, Abraham A, etal . Financial ties of principal investigators and randomized controlled trial outcomes: cross sectional study. BMJ 2017;356:6770. 10.1136/bmj. 677028096109

14 Stegenga J. Medical nihilism. Oxford University Press, 2018.

15 loannidis JP. The mass production of redundant, misleading, and conflicted systematic reviews and meta-analyses. Milbank Q 2016;94:485-514 .

10.1111/1468-0009.12210 27620683

16 Prescrire. Response to public consultation on "Evaluation of EMA fee system for the approval and monitoring of medicines." 2018. https://english.prescrire.org/Docu/ DOCSEUROPE/20180731_PrescrireResponseEMAfeeSystem.pdf

17 Darrow JJ, Avorn J, Kesselheim AS. Speed, safety, and industry funding-from PDUFA I to PDUFA VI. N Engl J Med 2017;377:2278-86. 10.1056/NEJMhle1710706 29211663

18 DeJong C, Aguilar T, Tseng CW, Lin GA, Boscardin WJ, Dudley RA. Pharmaceutical industry-sponsored meals and physician prescribing patterns for Medicare beneficiaries. JAMA Intern Med 2016;176:1114-22.

10.1001/jamainternmed.2016.276510.1001/jamainternmed.2016.2765 27322350

19 Wang AT, McCoy CP, Murad MH, Montori VM. Association between industry affiliation and position on cardiovascular risk with rosiglitazone: cross sectional systematic review. BMJ 2010;340:c1344. . 10.1136/bmi.c1344 20299696

20 Rose SL, Highland J, Karafa MT, Joffe S. Patient advocacy organizations, industry funding, and conflicts of interest. JAMA Intern Med 2017;177:344-50. 10.1001/jamainternmed.2016.8443 28114624

21 Kopp E, Lupki S, Lucas E. Patient advocacy groups take in millions from drugmakers. Is there a payback? Kaiser Health News 2018 Apr 6. https://khn.org/news/patient-advocacygroups-take-in-millions-from-drugmakers-is-there-a-payback

22 Pharmaceutical Research and Manufacturers of America. PhRMA code on interactions with healthcare professionals. https://www.phrma.org/Codes-and-guidelines/Code-onInteractions-with-Health-Care-Professionals

23 Spurling GK, Mansfield PR, Montgomery BD, etal . Information from pharmaceutical companies and the quality, quantity, and cost of physicians' prescribing: a systematic review. PLoS Med 2010;7:e1000352. 10.1371/journal.pmed. 100035220976098

24 Hadland SE, Rivera-Aguirre A, Marshall BDL, Cerdá M. Association of pharmaceutical industry marketing of opioid products with mortality from opioid-related overdoses. JAMA Netw Open 2019;2:e186007. . 10.1001/jamanetworkopen.2018.6007 30657529

25 Norris SL, Holmer HK, Ogden LA, Burda BU. Conflict of interest in clinical practice guideline development: a systematic review. PLoS One 2011;6:e25153.

10.1371/journal pone.0025153 22039406

26 Rothman DJ. Professional medical associations and divestiture from industry: an ethical imperative for pain society leadership. Pain Med 2016;17:218-9. 10.1093/pm/pnv041_2 26814303

27 loannidis JPA. Professional societies should abstain from authorship of guidelines and disease definition statements. Circ Cardiovasc Qual Outcomes 2018;11:e004889. 10.1161/CIRCOUTCOMES.118.004889 30354582

28 Jatoi I, Sah S. Clinical practice guidelines and the overuse of health care services: need for reform. CMAJ 2019;191:E297-8. 10.1503/cmaj.181496 30885967

29 Moynihan R, Brodersen J, Heath I, etal . Reforming disease definitions: a new primary care led, people-centred approach. BMJ Evid Based Med 2019;24:170-3. 10.1136/bmjebm-2018-111148 30962252

30 Campsall P, Colizza K, Straus S, Stelfox HT. Financial relationships between organization that produce clinical practice guidelines and the biomedical industry: a cross-sectional study. PLoS Med 2016;13:e1002029. . 10.1371/journal.pmed.1002029 27244653

31 World Health Organization Regional Office for Europe. Report of the 67th session of the WHO regional committee for Europe. Budapest, Hungary, 11-14 September 2017. http:/ /www.euro.who.int/ data/assets/pdf_file/0005/359096/67rp00e_FinalReport 170895. pdf?ua $=1$

32 European Ombudsman. Decision in strategic inquiry OI/7/2017/KR on how the European Medicines Agency engages with medicine developers in the period leading up to applications for authorisations to market new medicines in the EU, 17 Jul 2019. https:// www.ombudsman.europa.eu/en/decision/en/116683

33 Labour Party. Medicines for the many: public health before private profit. 21 Oct 2019. https://cancerunion.org/wp-content/uploads/2019/09/Medicines-For-The-Many.pdf.

34 Italian Medicines Agency (AIFA) Research and Development Working Group. Feasibility and challenges of independent research on drugs: the Italian medicines agency (AIFA) experience. Eur J Clin Invest 2010;40:69-86. 10.1111/j.1365-2362.2009.02226. x 20055898

35 Drugs for Neglected Diseases Initiative. 15 Years of needs-driven innovation for access. 2019. https://www.dndi.org/wp-content/uploads/2019/10/DNDi ModelPaper 2019.pdf

36 Rodwin MA. Independent drug testing to ensure drug safety and efficacy. $J$ Health Care Law Policy 2015;18:43-81.

37 Gaffney A, Lexchin JUSCanadian Pharmaceutical Policy Reform Working Group. Healing an ailing pharmaceutical system: prescription for reform for United States and Canada. BMJ 2018;361:k1039. 10.1136/bmj.k1039 29773533

38 Fried M. Prescription for poverty: drug companies as tax dodgers, price gougers, and influence peddlers. Oxfam, 2018. https://www.oxfam.org/en/research/prescription-poverty

39 Norwegian Medical Association. Statement about agreement between the association and the Norwegian Medicines Industry Association [undated and in Norwegian].: https:// beta.legeforeningen.no/om-oss/Styrende-dokumenter/legeforeningens-lover-og-andreorganisatoriske-regler/avtale-mellom-legemiddelindustriforeningen-og-den-norskelageforening-om-retningslinjer-for-samarbeid-og-samhandling-mellom-leger-legeforeningenog-legemiddelindustrien/\#23800

40 Moghimi Y. The "PharmFree" campaign: educating medical students about industry influence. PLoS Med 2006;3:e30. 10.1371/journal.pmed.0030030 16435890

41 Lexchin J. Doctors in denial: why big pharma and the Canadian medical profession are too close for comfort. Lorimer, 2017.

42 Kalantri SP. Drug industry and medical conferences. Indian J Anaesth 2004;48:28-30.

43 PLoS Medicine Editors. PLoS Medicine and the pharmaceutical industry. PLoS Med 2006:3:e329. . 10.1371/journal.pmed.0030329 17149970 
44 Jelinek GA, Brown AFT. A stand against drug company advertising. Emerg Med Australas 2011;23:4-6. 10.1111/j.1742-6723.2010.01393.x 21284808

45 Moynihan R, Macdonald H, Heneghan C, Bero L, Godlee F. Commercial interests, transparency, and independence: a call for submissions. BMJ 2019;365:11706. $10.1136 / \mathrm{bmj} .1170630992258$

46 About RELIS. 2015. https://relis.no/about_relis

47 Siemieniuk RA, Agoritsas T, Macdonald H, Guyatt GH, Brandt L, Vandvik PO. Introduction to BMJ Rapid Recommendations. BMJ 2016;354:5101.10.1136/bmi:5191 27080768 guidelines. [In Danish.] 2018. https://www.sst.dk/-/media/Opgaver/Patientforløb-og-kvalitet/ NKR/Metodehandbogen-2018.ashx?la=da\&

hash=22215410A43275099250C21574EB5787F2106857
49 National Health and Medical Research Council. Guidelines for guidelines: identifying and managing conflicts of interest. https://www.nhmrc.gov.au/guidelinesforguidelines/plan/ identifying-and-managing-conflicts-interest

50 Fabbri A, Santos A, Mezinska S, Mulinari S, Mintzes B. Sunshine policies and murky shadows in Europe: disclosure of pharmaceutical industry payments to health professionals in nine European countries. Int J Health Policy Manag 2018;7:504-9.

10.15171/ijhpm.2018.20 29935127

Published by the BMJ Publishing Group Limited. For permission to use (where not already granted under a licence) please go to http://group.bmj.com/group/rights-licensing/ permissions 